\title{
Analisis Tingkat Kesehatan Laporan Keuangan pada PT Bank Syariah Mandiri Tbk dengan Metode CAMEL Periode 2016 - 2020
}

\author{
Muhammad Iqbal Surya Pratikto, Nisha Nor Rahmawati \\ Universitas Islam Negeri Sunan Ampel Surabaya \\ muhammadiqbalsuryapratikto@gmail.com, nishanorr@gmail.com
}

\begin{tabular}{l}
\hline Article Info \\
\hline Article history: \\
Published: Dec 28,2021 \\
Page: $29-37$ \\
\hline
\end{tabular}

Keyword:

CAMEL, Bank Syariah

Mandiri, Kesehatan Bank

\section{Abstract \\ Tujuan adanya penelitian ini untuk melihat dan mengetahui tingkat kesehatan laporan keuangan yang ada pada PT Bank Syariah Mandiri Tbk menggunakan metode CAMEL yaitu (Capital, Asset Quality, Management, Earning and Liquidity) periode tahun 2016-2020 dengan rasio-rasio yang dipakai diantaranya adalah CAR, NPF, PDN, ROA, ROE, BOPO, NI dan FDR. Hasil yang diperoleh pada penelitian ini yaitu CAR, ROA, dan NI sangat sehat, NPF, ROE, FDR sehat, dan PDN, BOPO cukup sehat. \\ Kata kunci : CAMEL, Bank Syariah Mandiri, Kesehatan Bank}

The purpose of this research is to see and find out the level of soundness of the financial statements at PT Bank Syariah Mandiri Tbk using the CAMEL method (Capital, Asset Quality, The method of data collection used in this research is the documentation of secondary data sources that have been collected and have been documented on the bank's official website in the form of existing financial reports. The results obtained in this study are CAR, ROA, and NI very healthy, NPF, ROE, FDR healthy, and PDN, BOPO quite healthy.

Keywords : CAMEL, Mandiri Syariah Bank, Health Bank

\section{Pendahuluan}

Kinerja suatu perbankan bisa diketahui dari analisis laporan keuangan bank tersebut. Masyarakat akan lebih mempercayakan dana yang mereka punya untuk dikelola oleh bank jika bank tersebut memiliki kinerja yang sehat dan baik. Sebaliknya jika bank tersebut dianggap kurang baik dalam kinerja dan analisis laporan keuangannya tidak sehat maka masyarakat akan memilih bank

\section{Editorial Office:}

Prodi Ilmu Ekonomi Fakultas Ekonomi dan Bisnis Islam, UIN Sunan Ampel Surabaya

Jl. Ahmad Yani 117 Surabaya, Jawa Timur 60237, Indonesia.

Email: oje@uinsby.ac.id 
lain yang dianggap lebih baik (Fathimah, 2020). Dalam menjalankan bisnisnya bank juga harus mempertimbangkan resiko yang akan dihadapi. Ketika seorang nasabah menitipkan dana yang dimilikinya kepada bank maka bank tersebut harus dapat mengelolanya dengan baik. Seorang nasabah sewaktu-waktu bisa mengambil uang yang mereka miliki tersebut dan bank wajib memberikannya sesuai yang diminta oleh nasabah (M. Iqbal, 2019).

Kesalahan dalam bidang perbankan terlebih lagi dalam laporan keuangannya sering terjadi. Oleh karena itu adanya analisis laporan keuangan dibutuhkan agar dapat mengetahui transaksi keuangan yang terjadi bank tersebut. Untuk mengetahui pula tingkat kesehatan pada laporan keuangan bank sehingga ketika dirasa bank tersebut kurang sehat maka akan dilakukan perbaikan operasional yang dapat mengembalikan laporan keuangan sehingga menjadi baik. Karena dari tingkat kesehatan pada laporan keuangan tersebut dapat menjadi suatu hal yang penting untuk masyarakat sehingga mereka akan percaya dan berani untuk menitipkan dananya kepada bank tersebut.

Bank Muamalat Indonesia adalah bank syariah pertama yang berdiri di Indonesia pada tahun 1991. Sebelum adanya UU No. 7 Tahun 1992, keadaan bank syariah sulit untuk memperoleh perhatian yang baik dalam operasional perbankan nasional (Risa Dewi). Berganti dari UU No. 7 Tahun 1992 kemudian mulai berlaku UU No. 10 Tahun 1998 mengenai perubahan UU No. 7 Tahun 1992 yang membahas mengenai perbankan yang sudah memberi kesempatan besar untuk berkembangnya jaringan pada perbankan Syariah. Terdapat juga UU No.23 Tahun 1999 mengenai Bank Indonesia yang berisi penugasan untuk Bank Indonesia agar mempersiapkan peraturan-peraturan dan fasilitas pendukung yang dapat digunakan untuk membantu operasional bank Syariah. Pada kedua peraturan perundang-undangan di atas menjelaskan sebuah penerapan dual baking. Dimana hal tersebut menjadikan terciptanya dua sistem perbankan yaitu syariah dan juga konvensional secara beriringan (Risa Dewi).

Untuk menjaga kepercayaan masyarakat pada bank maka diperlukan adanya evaluasi pada kinerja bank. Evaluasi dilakukan untuk mengetahui tingkat kesehatan bank pada analisis laporan keuangannya. Karena hal ini sangat penting dilakukan agar masyarakat merasa yakin dan percaya untuk menitipkan dana yang mereka miliki. Pada metode analisis laporan keuangan ini dapat menguntungkan untuk banyak pihak tidak hanya pelaku nasabah melainkan juga manajemen perusahaan atau bank. Jika dirasa bank tersebut kinerjanya kurang baik dan laporan keuangannya tidak sehat maka dapat dibenahi kembali agar dapat menciptakan kenyamanan pada nasabah. Terdapat peraturan bank yang mengatur mengenai metode analisis laporan keuangan, yaitu analisis dengan metode CAMEL (Tika Dwi Apriani, 2021). Analisis dengan metode CAMEL berguna untuk mengetahui kinerja suatu perbankan dalam menentukan tingkat kesehatan laporan keuangan bank. Rasio metode CAMEL yang dipakai yaitu CAR, NPF, PDN, ROA, ROE, BOPO, NI dan FDR.

Bank yang akan dianalisis pada penelitian ini adalah PT Bank Syariah Mandiri Tbk. Jika dilihat dari perkembangannya Bank Syariah Mandiri merupakan bank syariah kedua setelah bank Muamalat Indonesia. Pada pelayanannya Bank Mandiri sangat baik bahkan pelayanannya terbaik di Indonesia. Bank Mandiri juga menguasai sebagian pangsa pasar perbankan yang berada di Indonesia. Kinerja pada Bank Mandiri ataupun Bank Syariah Mandiri harus selalu dijaga dengan baik, oleh karena itu pada tingkat kesehatan laporan keuangan harus selalu sehat agar dapat membuat masyarakat percaya atas kinerja yang dilakukan oleh bank. Karena tingkat kepercayaan nasabah sangat mempengaruhi perkembangan suatu bank. 
Berdasarkan pada uraian yang telah dibahas di atas, oleh karena itu penulis tertarik untuk membuat penelitian terhadap Laporan Keuangan pada Bank Syariah Mandiri sebagai penilaian terhadap tingkat kesehatan bank. Adapun judul yang dibahas oleh penulis adalah "Analisis Tingkat Kesehatan Laporan Keuangan pada PT Bank Syariah Mandiri Tbk dengan Metode CAMEL Periode 2016 - 2020"

Permasalahan yang ada pada penelitian ini yaitu bagaimana tingkat atau taraf kesehatan laporan keuangan pada Bank Syariah Mandiri dengan memakai metode CAMEL dan jika dilihat dari permasalahan tersebut mempunyai tujuan untuk memahami dan mengetahui tingkat kesehatan laporan keuangan pada Bank Syariah Mandiri dengan metode CAMEL.

\section{Tinjauan Pustaka}

\section{a.Bank}

Pengertian bank secara umum yaitu tempat untuk menghimpun dana yang berasal dari masyarakat untuk dikelola maupun disimpan dan bisa diambil kapan saja oleh seseorang yang disebut nasabah sesuai dengan perjanjian awal antara kedua belah pihak (M. Iqbal, 2019). Dijelaskan pada UU No. 7 Tahun 1992 Pasal 1 yang selanjutnya dirubah menjadi UU No. 10 Tahun 1998 yang membahas mengenai Perbankan (Riandi Chandra, 2016) yang berbunyi "Bank merupakan suatu badan usaha yang menghimpun dana yang berasal dari masyarakat dalam bentuk simpanan kemudian disalurkan ke masyarakat dalam bentuk kredit dan atau dalam bentuk-bentuk lainnya dalam rangka meningkatkan taraf hidup masyarakat banyak".

\section{b.Bank Syariah}

Pengertian bank syariah (Purwanti, 2015) merupakan bank yang tata cara beroperasinya harus sama dengan syariat Islam. Segala ketentuan sudah ada dalam AlQur'an dan Hadist. Bank yang segala bentuk transaksinya mengacu pada aturan-aturan Islam. Menghindari adanya unsur yang mengandung riba yang telah dilarang oleh Rasulullah. (M. Iqbal, 2019) menjelaskan bahwa bank syariah merupakan bank yang dalam menjalankan bisnisnya selalu berpegang pada hukum-hukum Islam. Pada setiap kegiatannya tidak menambahkan unsur bunga dan hal-hal lain yang dilarang oleh Islam. Pada bank syariah terdapat akad yang sesuai dengan syarat dan rukun Islam.

\section{c.Laporan Keuangan}

Laporan keuangan merupakan suatu catatan keadaan sebuah lembaga keuangan pada waktu tertentu. Kondisi perusahaan pada waktu tertentu yang dimaksud adalah pada saat keadaan perusahaan keuangan pada tanggal, bulan dan tahun tertentu. Untuk mengetahui kondisi perusahaan dalam keadaan baik atau kurang baik (Dr. Kasmir, 2019). Laporan keuangan harus disajikan dengan sebenar-benarnya data karena jika salah maka dapat merugikan perusahaan atau lembaga keuangan lainnya. Tujuan adanya laporan keuangan secara umum dapat memberikan sebuah informasi tentang jumlah aktiva dan jumlah kewajiban pada perusahaan atau perbankan. Dari informasi yang didapat pada laporan keuangan dapat menentukan tingkat kesehatan suatu bank.

\section{d.Tingkat Kesehatan Bank}

Tingkat kesehatan bank adalah hal yang sangat penting, segala kegiatan yang dilakukan oleh bank telah tercatat dalam 
laporan keuangan bank. Hasil dari laporan keuangan tersebut bisa diketahui tingkat kesehatan pada bank tersebut. Bank bisa disebut sehat ketika bank tersebut bisa menjaga kepercayaan dari masyarakat. Tingkat kepercayaan dari masyarakat dapat meningkatkan nilai suatu perbankan agar lebih berkembang.

\section{e.Metode CAMEL}

Metode CAMEL menurut peraturan Bank Indonesia No. 6/10/PBI/2004 tanggal 12 April 2004 tentang Sistem Penilaian Tingkat Kesehatan Bank Umum, yang berisi Capital (modal), Asset Quality (kualitas aktiva), Management (manajemen), Earning (rentabilitas) dan Liquidity (likuiditas). Pada setiap variabel menjelaskan rasio-rasio diantaranya adalah CAR, NPF, PDN, ROA, ROE, BOPO, NI dan FDR.

\section{Metode Penelitian}

Pada penelitian ini penulis memakai metode deskriptif kuantitatif, yaitu jenis penelitian yang menggambarkan mengenai kondisi sebagai point penting pada penelitian tersebut ditinjau dari data berupa angka yang telah dikumpulkan. Jenis data yang dipakai pada penelitian ini merupakan data sekunder, yaitu data yang sudah dikumpulkan oleh lembaga pengumpul data dan sudah terpublikasikan di kalangan masyarakat pengguna data. Sumber data pada penelitian berasal ini dari website resmi. Metode pengumpulan data yang dipakai pada penelitian ini merupakan dokumentasi dari pengumpulan data dengan cara mengumpulkan data sekunder yang telah didokumentasikan berupa laporan keuangan tahunan pada Bank yang bersangkutan. Untuk mengetahui taraf kesehatan laporan keuangan pada PT Bank Syariah Mandiri dengan metode CAMEL periode tahun 2016-2020, maka dapat dijelaskan dengan beberapa rasio sebagai berikut :

\section{Capital (Permodalan)}

Modal merupakan hal yang penting dan dibutuhkan pada saat seseorang ingin membangun atau mengembangkan usaha yang dimilikinya. Sutau modal dapat diperoleh dari lembaga keuangan berupa pinjaman dan dapat dikembalikan sesuai dengan perjanjian di awal oleh kedua belah pihak. (Yunita, 2018) Rasio yang dipakai untuk mengukur kecukupan capital pada bank syariah yaitu dengan memakai rasio CAR (Capital Adequacy Ratio). Capital Adequancy Rasio yaitu rasio permodalan yang memberitahukan tentang kemampuan suatu bank dalam menyediakan dana yang dipakai untuk keperluan membangun atau pengembangan usaha serta menampung kemungkinan adanya risiko kerugian yang diakibatkan oleh operasional perbankan. Adapun rumus yang dipakai untuk mengukur CAR adalah sebagai berikut:

$$
\mathrm{CAR}=\frac{\text { Modal }}{\text { ATMR }} \times 100 \%
$$

Tabel 1. Klasifilkasi Peringkat CAR

\begin{tabular}{|c|c|c|}
\hline Peringkat & Nillai Komposit & Predikat \\
\hline 1 & CAR lebih dari sama dengan 12\% & Sangat Sehat \\
\hline 2 & 9\% kurang dari sama dengan CAR kurang dari 12\% & Sehat \\
\hline 3 & 8\% kurang dari sama dengan CAR kurang dari $9 \%$ & Cukup Sehat \\
\hline 4 & 6\% kurang dari sama dengan CAR kurang dari $8 \%$ & Kurang Sehat \\
\hline j & CAR kurang dari sama dengan $6 \%$ & Tidak Sehat \\
\hline
\end{tabular}

\section{Asset Quality (Kualitas Aset)}

Aspek ini berguna untuk mengetahui nilai jenis-jenis asset yang dimiliki oleh lembaga keuangan atau perbankan. Penilaian terhadap asset harus sama dengan Peraturan yang sudah ditetapkan oleh Bank Indonesia dengan membandingkan antara aktiva produktif dengan aktiva produktif diklasifikasikan. Rasio yang dipakai adalah 
rasio NPF (Non Performing Financing). Berdasarkan surat edaran dari BI No.3/30DPNP tanggal 14 Desember 2001, NPF dapat diukur dari rasio perbandingan antara kredit bermasalah dengan total kredit yang diberikan. Adapun rumus yang dapat dipakai untuk mengukur NPF adalah sebagai berikut:

$$
\mathrm{NPF}=\frac{\text { Kredit Bermasalah }}{\text { Total } \text { Kredit }} \times 100 \%
$$

Tabel 2. Klasifikasi Peringkat NPF

\begin{tabular}{|c|l|c|}
\hline Peringkat & \multicolumn{1}{|c|}{ Nilai Komposit } & Predikat \\
\hline 1 & NPFkurang dari sama dengan 2\% & Sangat Sehat \\
\hline 2 & $2 \%$ kurang dari sama dengan NPF kurang dari 5\% & Sehat \\
\hline 3 & $5 \%$ kurang dari sama dengan NPF kurang dari $8 \%$ & Cukup Sehat \\
\hline 4 & $8 \%$ kurang dari sama dengan NPF kurang dari 12\% & Kurang Sehat \\
\hline 5 & NPF lebih dari sama dengan $12 \%$ & Tidak Sehat \\
\hline
\end{tabular}

\section{Management (Manajemen)}

Manajemen merupakan tolok ukur masyarakat dalam menentukan tingkat kepercayaan masyarakat pada lembaga keuangan atau perbankan tersebut. Tentunya manajemen yang baik akan berpengaruh terhadap kualitas suatu perbankan tersebut. Hal ini perlu ditekankan kepada manajer perusahaan agar dapat memberikan laporan perusahaan dengan baik. Hal tersebut dilakukan agar tidak adanya dana yang tertimbun secara berlebihan pada bank yang bersangkutan (Sulisnaningrum, 2019). Penilaian terhadap faktor manajemen dapat dinilai dengan menggunakan rasio Posisi Devisa Netto (PDN). Adapun rumus yang bisa dipakai untuk menganalisis PDN yaitu sebagai berikut:

$$
\text { PDN }=\frac{\text { Selisih Aset dan Liabitas Valas }}{\text { Total Modal }} \times \mathbf{1 0 0} \%
$$

Tabel 3. Klasifikasi Peringkat PDN

\begin{tabular}{|c|l|c|}
\hline Peringkat & \multicolumn{1}{|c|}{ Nilai Komposit } & Predikat \\
\hline 1 & Tidak ada pelanggaran rasio PDN & Sangat Sehat \\
\hline 2 & $\begin{array}{l}\text { Tidak ada pelanggaran rasio PDN namun pernah } \\
\text { melakukan pelanggaran dan telah terselesaikan }\end{array}$ & Sehat \\
\hline 3 & $\begin{array}{l}\text { Pelanggaran rasio PDN lebih dari0\% sampai dengan } \\
\text { kurang dari 10\% }\end{array}$ & Cukup Sehat \\
\hline 4 & $\begin{array}{l}\text { Pelanggaran rasio PDN lebih dari 10\% sampai dengan } \\
\text { kurang dari 25\% }\end{array}$ & Kurang Sehat \\
\hline 5 & Pelanggaran PDN lebih dari 25\% & Tidak Sehat \\
\hline
\end{tabular}

\section{Earning (Rentabilitas)}

Analisis terhadap faktor rentabilitas adalah analisis untuk mengetahui kemampuan suatu bank dalam menghasilkan laba atau peendapatan (Triandini, 2012). Jika pada suatu perbankan dalam operasionalnya terus mengalami kerugian maka berdampak pada penurunan modal. Penilaian terhadap faktor rentabilitas dapat dianalisis dengan menggunakan rasiorasio seperti ROA (Return On Assets), ROE (Return On Equity), BOPO (Biaya Operasional Terhadap Pendapatan Operasional) dan NI (Net Imbalan). Adapun rumus yang dapat dipakai dalam menganalisis ROA, ROE, BOPO dan NI yaitu sebagai berikut:

a) Rumus ROA (Return On Assets)

$$
\text { ROA }=\frac{\text { Laba Sebelum Pajak }}{\text { Rata-rata Total Aset }} \times 100 \%
$$

Tabel 4. Klasifikasi Peringkat ROA

\begin{tabular}{|c|l|c|}
\hline Peringkat & \multicolumn{1}{|c|}{ Nilai Komposit } & Predikat \\
\hline 1 & ROA lebin dari sama dengan 2\% & Sangat Sehat \\
\hline 2 & $1,26 \%$ kurang dari sama dengan R0A kurang dari $5 \%$ & Sehat \\
\hline 3 & $0,51 \%$ kurang dari sama dengan ROA kurang dari 1,25\% & Cukup Sehat \\
\hline 4 & $0 \%$ kurang dari sama dengan ROA kurang dari $0,5 \%$ & Kurang Sehat \\
\hline 5 & ROA kurang dari $0 \%$ & Tidak Sehat \\
\hline
\end{tabular}

b) Rumus ROE (Return On Equity)

$$
\mathrm{ROE}=\frac{\text { Laba Setelah } \text { Pajak }}{\text { Rata-rata Total Modal }} \times 100 \%
$$


Tabel 5. Klasifikasi Peringkat ROE

\begin{tabular}{|c|c|c|}
\hline Peringkat & Nillai Komposit & Predikat \\
\hline 1 & ROE lebil dari sama dengan $20 \%$ & Sangat Sehat \\
\hline 2 & 12,51\% kurang dari sama dengan ROE kurang dari $20 \%$ & Sehat \\
\hline 3 & $5,01 \%$ kurange dari sama dengan ROE kurang dari 12,5\% & Cukup Sehat \\
\hline 4 & O\% kurang dari sama dengan ROE kurang dari $5 \%$ & Kurang Sehat \\
\hline j & ROE kurang dari O\% & Tidak Sehat \\
\hline
\end{tabular}

c) Rumus BOPO (Biaya Operasional Terhadap Pendapatan Operasional)

$$
\mathrm{BOPO}=\frac{\text { Biaya Operasional }}{\text { Pendapatan Operasional }} \times 100 \%
$$

Tabel 6 Klasifikasi Peringkat BOPO

\begin{tabular}{|c|c|c|}
\hline Peringkat & Nilai Komposit & Predikat \\
\hline 1 & $<88 \%$ & Sangat Sehat \\
\hline 2 & $89 \% \cdot-93 \%$ & Sehat \\
\hline 3 & $94 \% \cdot 96 \% \%$ & Cukup Sehat \\
\hline 4 & $97 \% \cdot 100 \%$ & Kurang Sehat \\
\hline 5 & $>100 \%$ & Tidak Sehat \\
\hline
\end{tabular}

d) Rumus NI (Net Imbalan)

$$
\mathbf{N I}=\frac{\text { Pendapatan Imbal }}{\text { Rata-rata Aset Produktif }} x \mathbf{1 0 0} \%
$$

Tabel 7 Klasifikasi Peringkat NI

\begin{tabular}{|c|l|c|}
\hline Peringkat & \multicolumn{1}{|c|}{ Nïlai Komposit } & Predikat \\
\hline 1 & NI lebih dari sama dengan 6,5\% & Sangat Sehat \\
\hline 2 & $2,01 \%$ kurang dari sama dengan NI kurang dari 6,5\% & Sehat \\
\hline 3 & $1,5 \%$ kurang dari sama dengan NI kurang dari 2\% & Cukup Sehat \\
\hline 4 & $0 \%$ kurang dari sama dengan NI kurang dari 1,49\% & Kurang Sehat \\
\hline 5 & NI kurang dari 0\% & Tidak Sehat \\
\hline
\end{tabular}

\section{Liquidity (Likuiditas)}

Pada analisis likuiditas digunakan untuk mengetahui kemampuan bank dalam menutupi atau melunasi hutang-hutang jangka pendeknya yang telah jatuh tempo (Tika Dwi Apriani, 2021). Untuk mengetahui faktor likuiditas ini bisa memakai FDR (Financing to Deposit Ratio). Adapun rumus yang digunakan untuk mengukur PDN adalah sebagai berikut:

FDR $=\frac{\text { Jumlah Kredit } \text { yang diberikan }}{\text { Total Dana Pihak Ketiga }} \boldsymbol{x 1 0 0} \%$
\begin{tabular}{|c|l|c|}
\hline \multicolumn{1}{|c|}{ Tabel 8 Klasifikasi Peringkat FDR } & Prlai Komposit & Predikat \\
\hline 1 & $\begin{array}{l}\text { Rasio lebih dari } 50 \% \text { sampai dengan kurang dari sama } \\
\text { dengan } 75 \%\end{array}$ & Sangat Sehat \\
\hline 2 & $\begin{array}{l}\text { Rasio lebih dari 75\% sampai dengan } \\
\text { kurang dari sama dengan } 85 \%\end{array}$ \\
\hline 3 & $\begin{array}{l}\text { Rasio kurang dari } 85 \% \text { sampai dengan kurang dari sama } \\
\text { dengan } 100 \%\end{array}$ & Cukup Sehat \\
\hline 4 & $\begin{array}{l}\text { Rasio lebih dari } 100 \% \text { sampai dengan kurang dari sama } \\
\text { dengan } 120 \%\end{array}$ & Kurang Sehat \\
\hline 5 & Lebih dari $120 \%$ & Tidak Sehat \\
\hline
\end{tabular}

\section{Pembahasan}

\section{Capital (Modal)}

Gambar l. Grafik hasil penilaian rasio CAR pada PT Bank Syariah Mandiri Tbk Tahun 2016-2020

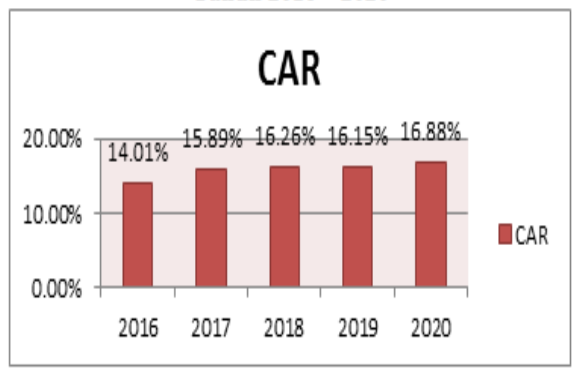

Dilihat dari hasil grafik pada gambar 1 bisa dipahami bahwa analisis CAR PT Bank Syariah Mandiri Tbk tahun 2016 sebanyak $14,01 \%$, kemudian pada tahun selanjutnya yaitu 2017 naik menjadi $15,89 \%$, semakin meningkat kembali pada tahun 2018 menjadi $16,26 \%$, namun terjadi penurunan sehingga menjadi $16,15 \%$ pada tahun 2019, dan pada tahun 2020 kembali meningkat menjadi $16,88 \%$. Maka dari analisis tersebut bisa disimpulkan bahwa analisis CAR pada PT Bank Syariah Mandiri Tbk periode 2016 - 2020 termasuk dalam kategori sangat sehat.

2.Asset Quality (Kualitas Aset) 
Gambar 2. Grafik hasil penilaian rasio NPF pada PT Bank Syariah Mand Tahun 2016-2020

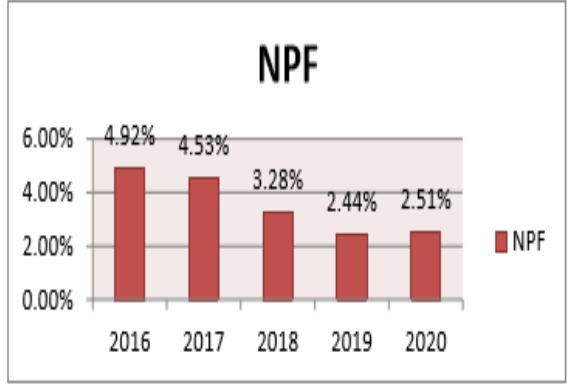

Dilihat dari hasil grafik pada gambar 2 di atas maka dapat dipahami bahwa analisis NPF PT Bank Syariah Mandiri Tbk pada tahun 2016 sebanyak 4,92\%, kemudian pada tahun selanjutnya yaitu 2017 turun menjadi $4,53 \%$, kembali menurun pada tahun 2018 menjadi 3,28\%, dan semakin penurunan hingga menjadi $2,44 \%$ pada tahun 2019, dan pada tahun 2020 kembali meningkat menjadi $2,51 \%$. Maka dari analisis tersebut bisa disimpulkan bahwa analisis NPF pada PT Bank Syariah Mandiri Tbk periode 2016 - 2020 termasuk dalam kategori sehat.

\section{Management (Manajemen)}

\section{Gambar 3. Grafik hasil penilaian rasio PDN pada PT Bank Syariah Mandiri Tbk} Tahun 2016-2020

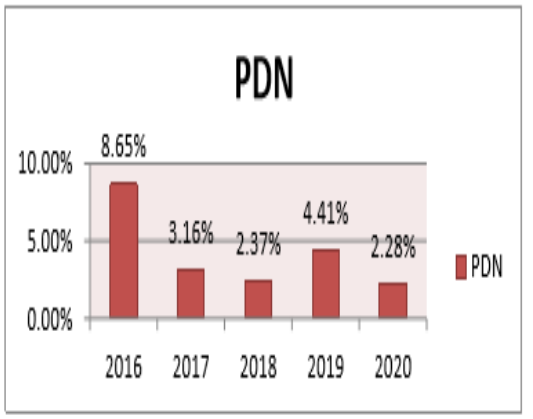

Dilihat dari hasil grafik pada gambar 3 di atas maka bisa dipahami bahwa analisis PDN PT Bank Syariah Mandiri Tbk tahun 2016 sebanyak 8,65\%, kemudian tahun selanjutnya yaitu 2017 turun menjadi 3,16\%, kembali menurun pada tahun 2018 menjadi 2,37\%, dan mengalami kenaikan hingga menjadi $4,41 \%$ pada tahun 2019 , dan pada
2020 mengalamai penurunan kembali menjadi 2,28\%. Maka dari analisis tersebut bisa dijelaskan bahwa analisis PDN PT Bank Syariah Mandiri Tbk periode 2016 - 2020 termasuk dalam kategori cukup sehat.

4.Earning (Rentabilitas)

a) ROA (Return On Assets)

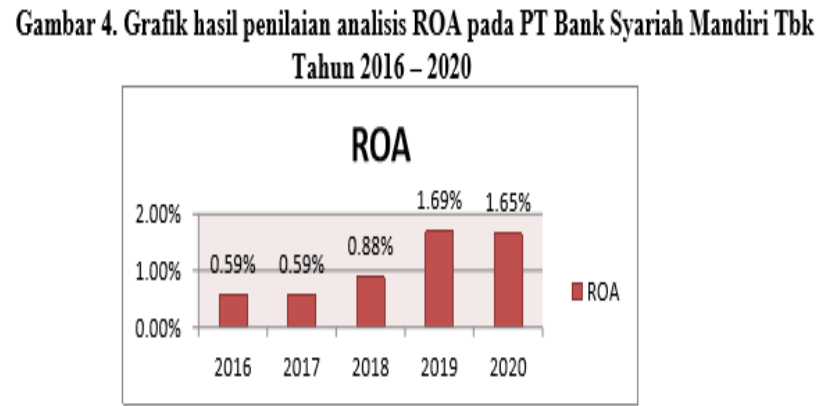

Dilihat dari hasil grafik dalam gambar 4 maka bisa dipahami bahwa analisis ROA pada PT Bank Syariah Mandiri Tbk tahun 2016 sebanyak 0,59\%, kemudian tahun selanjutnya yaitu 2017 tetap sama sebanyak $0,59 \%$, mengalami peningkatan pada tahun 2018 menjadi $0,88 \%$, dan kembali naik hingga menjadi $1,69 \%$ pada tahun 2019, dan tahun 2020 menurun menjadi $1,65 \%$. Maka dari hasil tersebut dapat diketahui bahwa ROA pada PT Bank Syariah Mandiri Tbk periode 2016 - 2020 termasuk kategori sangat sehat.

\section{b) ROE (Return On Equity)}

\section{Gambar 5. Grafik hasil penilaian analisis ROE pada PT Bank Syariah Mandiri Tbk} Tahun 2016-2020

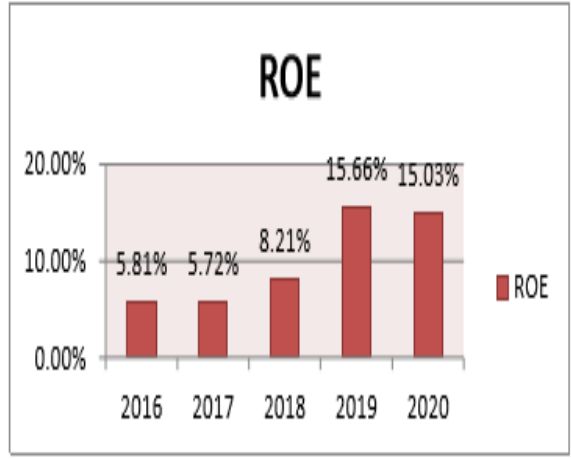


Dilihat dari hasil grafik pada gambar 5 maka dapat dipahami bahwa analisis ROE PT Bank Syariah Mandiri Tbk tahun 2016 sebanyak $5,81 \%$, kemudian pada tahun selanjutnya yaitu 2017 turun menjadi 5,72\%, mengalami peningkatan pada tahun 2018 menjadi $8,21 \%$, dan kembali naik hingga menjadi $15,66 \%$ pada tahun 2019 , dan pada tahun 2020 menurun menjadi 15,03\%. Maka dari hasil tersebut dapat diketahui bahwa ROE pada PT Bank Syariah Mandiri Tbk periode 2016 - 2020 termasuk golongan sehat.

c) BOPO (Biaya Operasional Terhadap Pendapatan Operasional)

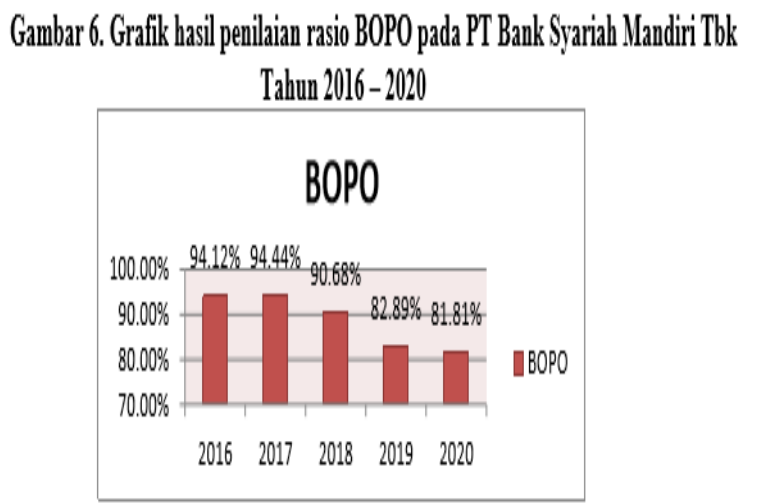

Dilihat dari hasil grafik pada gambar 6 bisa dinilai bahwa rasio BOPO pada PT Bank Syariah Mandiri Tbk pada tahun 2016 sebesar 94,12\%, kemudian pada tahun selanjutnya yaitu 2017 mengalami kenaikan menjadi 94,44\%, turun pada tahun 2018 menjadi $90,68 \%$, dan terus turun hingga menjadi $82,89 \%$ pada tahun 2019 , dan pada tahun 2020 turun kembali menjadi 81,81\%. Maka dari analisis tersebut bisa diketahui bahwa rasio BOPO PT Bank Syariah Mandiri Tbk periode 2016 - 2020 termasuk dalam kategori cukup sehat.

d) NI (Net Imbalan)
Gambar 7. Grafik hasil penilaian rasio NI pada PT Bank Syariah Mandiri Tbk Tahun 2016-2020

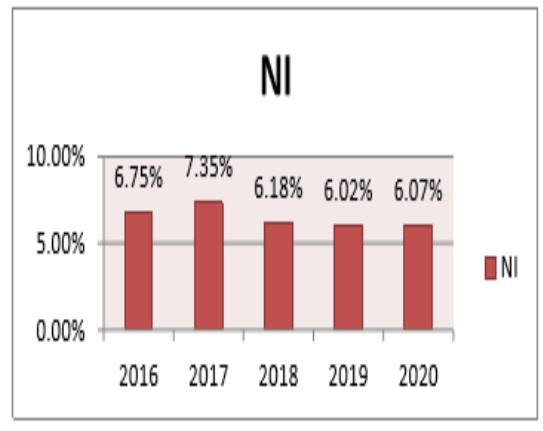

Dilihat dari hasil grafik pada gambar 7 bisa ditarik kesimpulan bahwa rasio NI pada PT Bank Syariah Mandiri Tbk pada tahun 2016 sebanyak 6,75\%, kemudian pada tahun selanjutnya yaitu 2017 mengalami kenaikan menjadi 7,35\%, menurun pada tahun 2018 menjadi $6,18 \%$, dan terus menurun hingga menjadi $6,02 \%$ pada tahun 2019, dan pada tahun 2020 naik kembali menjadi $6,07 \%$. Maka dari analisis tersebut bisa dipahami bahwa rasio NI pada PT Bank Syariah Mandiri Tbk periode 2016 - 2020 termasuk dalam kategori sangat sehat.

e) Liquidity (Likuiditas)

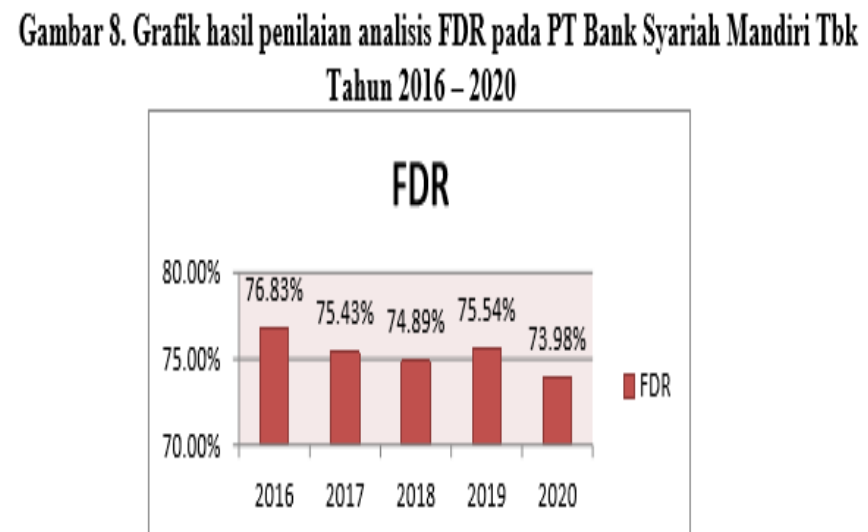

Dilihat dari hasil grafik pada gambar 8 maka dapat ditarik kesimpulan bahwa analisis FDR PT Bank Syariah Mandiri Tbk pada tahun 2016 sebanyak 76,83\%, kemudian pada tahun selanjutnya yaitu 2017 mengalami penurunan menjadi $75,43 \%$, terjadi penurunan kembali pada tahun 2018 menjadi $74,89 \%$, dan selanjutnya 
mengalami kenaikan hingga menjadi $75,54 \%$ pada tahun 2019 , dan pada tahun 2020 menurun kembali menjadi 73,98\%. Maka dari analisis tersebut bisa dinilai bahwa rasio FDR PT Bank Syariah Mandiri Tbk periode 2016 - 2020 termasuk dalam kategori sehat.

\section{Kesimpulan}

Menurut hasil penelitian yang sudah dibahas bisa diketahui bahwa penelitian CAR pada tahun 2016 - 2020 tergolong kategori sangat sehat. Selanjtnya pada analisis NPF termasuk dalam kategori sehat. Pada analisis PDN masuk dalam kategori cukup sehat. Pada earning terdapat rasio ROA yang hasil analisisnya sangat sehat pada tahun 2016 - 2020, dilanjutkan dengan ROE masuk dalam kategori sehat. Pada analisis BOPO hasil yang didapat adalah masuk dalam kategori cukup sehat, analisis NI menyatakan bahwa laporan keuangan sangat sehat, dan yang terakhir analisis dengan FDR bahwa hasil yang didapat masuk dalam kategori sehat.

Jika dilihat pada simpulan tersebut, maka saran yang tepat adalah diharapkan kepada PT Bank Syariah Mandiri Tbk agar dapat meningkatkan kembali tingkat kesehatan pada laporan keuangannya, karena hal tersebut dapat menjadi penentu kinerja suatu perbankan.

\section{Daftar Pustaka}

Dr. Kasmir, S. M. (2019). Analisis Laporan Keuangan. Depok: Rajawali Pers.

Fathimah, V. (2020, September). Analisis Kinerja Keuangan Bank Syariah Mandiri dengan Metode CAMEL. Jurnal Studi Manajemen, 2, 197 205.

M. Iqbal, A. Q. (2019, April). Analisis Tingkat Kesehatan dan Potensi Financial Distress dengan Metode RGEC pada BNI Syariah Tahun 2014-2018. Journal of Islamic
Economics and Business, 9(1), 87101.

Purwanti, S. E. (2015, Januari). Analisis Tingkat Kesehatan Bank dengan Metode CAMEL pada Bank Muamalat Indonesia, Bank Syariah Mandiri, dan BNI Syariah. Artikel Publik Ilmiah.

Riandi Chandra, M. M. (2016). Analisis Kinerja Keuangan PT Bank Syariah Mandiri dan PT Mandiri Tbk dengan Menggunakan Metode CAMEL. Jurnal Berkala Ilmial Efisiensi, 16(2), 429-435.

Risa Dewi, R. M. (n.d.). Analisis Tingkat Kesehatan Bank dengan Menggunakan Metode CAMEL pada PT Bank Syariah Mandiri (Studi Kasus pada PT Bank Syariah Mandiri Cabang Ambon). Jurnal Riset Manajemen, 130-145.

Sulisnaningrum. (2019). Analisis Kinerja Keuangan Bank dengan Metode CAMEL pada Bank Muamalat dan Bank Syariah Mandiri di Surabaya. Akuntansi Jaya Negara, 11(1), 1-9.

Tika Dwi Apriani, A. T. (2021, Juli). Perbandingan Tingkat Kesehatan Bank pada PT Bank Syariah Mandiri dengan PT Bank Mandiri Tbk Menggunakan Metode CAMEL (Periode 2017-2019). Jurnal Ekonomi Akuntansi.

Triandini. (2012). Analisis Kinerja Keungaan dengan Menggunakan CAMEL Sebagai Metode untuk Mengukur Tingkat Kesehatan Bank (Studi pada PT Bank Syariah Mandiri Tbk). SKRIPSI. Mlalang.

Yunita, N. A. (2018). Analisis Tingkat Kesehatan Bank dengan Menggunakan Metode CAMELS dan PEARLS pada Bank Umum di Indonesia. Aceh: CV. SEFA BUMI PERSADA. 